IIV FOR TECHNISCHES MESSEN I NDUSTRIELLE MESSTECHN IK let von Georg Keinath. Herausgegeben von Franz unter Mitarbeit von L. Merz und L. Brandenburger 1. Oldenbourg KG, München 8 , Rosenheimer Str. 145, Tel. 449831 ber $052 / 3789$

orflich für den Archivfeil:

ng. Franz Moeller, Braunschwelg, Peslalozzistraße 4

orflich für den Zeitschriftenteil:

Lou is Merz, Karlsruhe/B., Vincentiuss'raße 12

Leo Brandenburger, Karlsruhe/B. Germershoimer Straße 10

le, besonders die des Nachdrucks und cer Oberselzung (auch eise), vorbehalten. Ohne ausdrückliche Genehmigung des Ver. es auch nicht gestartet, dieses Helt, einzelne Beiträge oder Teile

of photomechanischem Wege (Photokopie, Mikrokopie) zu verin.

ige (Erstveröffentlichungen), die in das Gebiet des Lleferwerkes d an die Schriftleilung zu senden.

\title{
LTSVERZEICHN IS
}

\section{Iriftenteil}

25 Jzhre „Archiv für technisches Messen“ R 65 Georg Keinsth, der Begründer des ATM R 66 Sorge, Grundsätzliches über das digitale Messen . . . . . . . . . . . . . . R 67

Schneider, Ein thermischer Überlast- und Fehlerschutz für Transformatoren mit Öl R 70 Neue Instrumente . . . . . . . . . R 74 Buchbesprechungen .........R 77 Persönliches .............. R 78 Kurznachrichten aus Wirtschaft und Industrie ............... R78 Internationale Vereinigung für das Analogie-Rechnen ............. . R79 Zeitschriftenschau .......... R 79

1-4 Flügge, Johanres, Messungen in der feinoptischen Fertigung . . . . . . . . 145

1-2 Berndt, G., Längenmaße im Austauschbau 149

3-2 Schwaibold, Erich, Der Hallefekt und seine technische Anwendung. I. Grundlagen und Hallgeneratoren ............ 153

6-1 Toeller, H., Hufbaver, W., Der Lichtzeiger als Bauelement elektrischer Meßgeräte I . . 157

1-5 Emschermann, Hans Heinrich, Die Darstellung von Meßwerten in Zahlenform . . . . . 161

3-3 Korte, $H$., Technische Lichtmeßgeräte . . 165

4-15 AEG, Der Thermoumformer-Kompensator der AEG (Wechselstromnormal) . . . . . 167

Juli 1956

Seite 145-168

Lieferung $\mathbf{2 4 0}$

AG R. OLDENBOURG . MUNCHEN
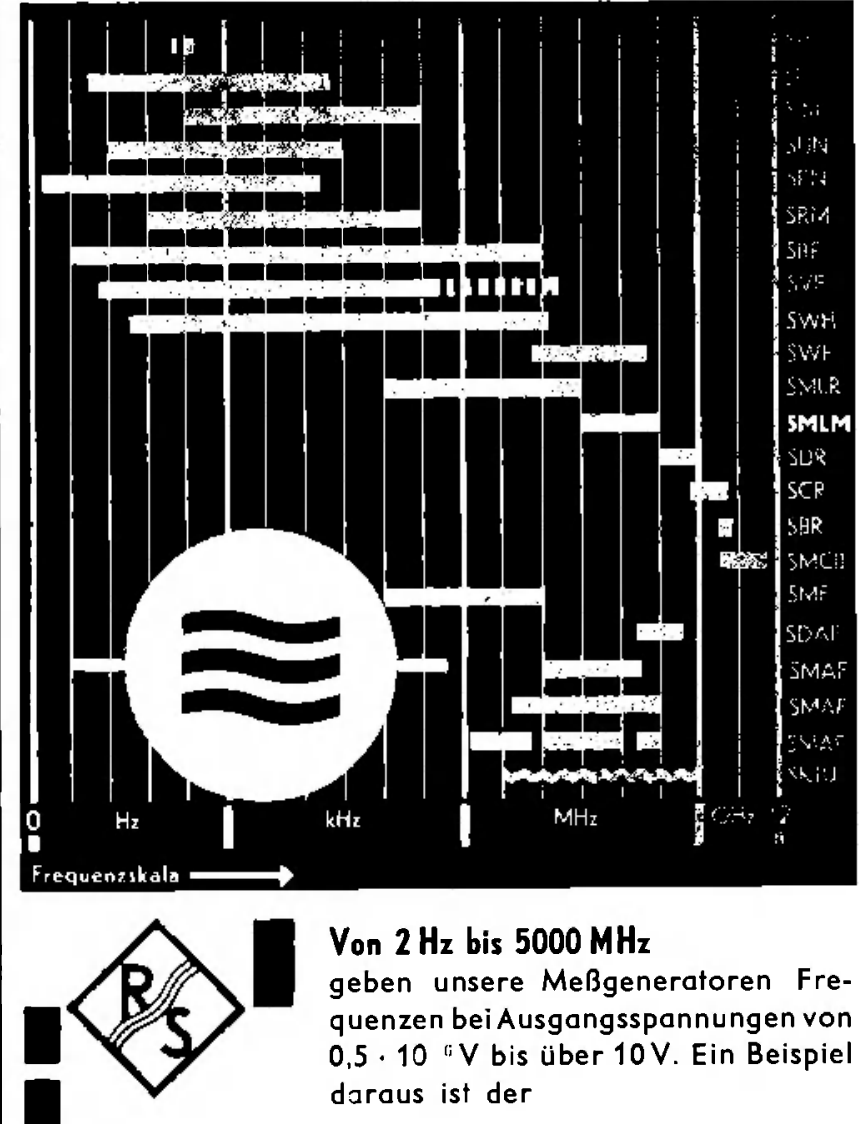

\section{Leistungs-Meßsender \\ Type SMLM}

Frequenzbereich $30 \mathrm{MHz}$ bis $300 \mathrm{MHz}$

Fehlergrenzen ....... $\pm 1 \%$

Ableseungenauigkeit auf der

Frequenzskala ....... $1 \% 1 \%$

Maximale Ausgangsspannung

an $60 \Omega$ Belastung . ....... $3 \mathrm{~V}$

Eigenmodulation. . . . . . AM rd. $1000 \mathrm{~Hz}$ rd. $80 \%$

Fremdmodulation ...... AM $30 \mathrm{~Hz} \cdots 200 \mathrm{kHz}$ max. etwa $80 \%$

Modulationsklirrfaktor bei

angepaßtem Verbraucher und

$\mathrm{m}=30 \% \ldots \ldots<1 \%$

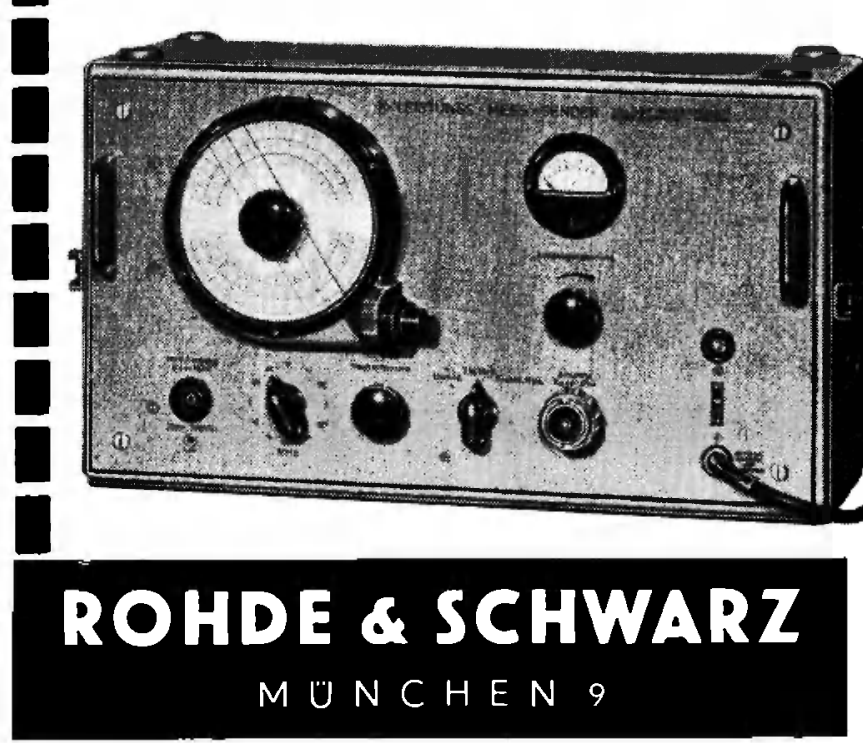




\section{Ständige Weiterentwicklung}

auf allen Gebieten der Elektromeßtechnik ist $\epsilon$ unserer wichtigsten Aufgaben. Jeder vierte $A$ steltte unseres Wernerwerkes für Meßtechnik Is der Entwicklung tätig.

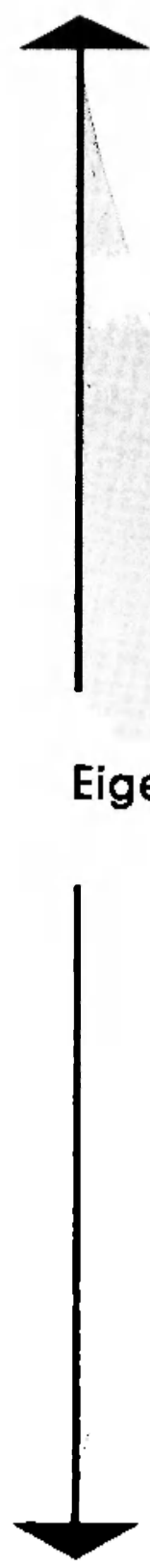

\section{SIEMENS \\ MESSTECHNIK

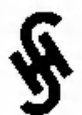

igenverbrauch - Meßwert 